\title{
Corrosion behavior of vacuum plasma sprayed Ti-Zr-Ni quasicrystal coatings
}

\author{
P. P. BANDYOPADHYAY $\ddagger$, P. KERN, S. SIEGMANN* \\ Swiss Federal Laboratories of Materials Testing and Research (EMPA), Thun, Switzerland \\ E-mail: stephan.siegmann@empa.ch
}

The discovery of quasicrystal [1] phases has been reported in 1984. Such phases offer outstanding material properties, e.g., high hardness, low friction coefficient, low surface energy, high thermoelectric power [2-6] etc. Hence, quasicrystals are potential candidates for many industrial applications [7-9].

To date, quite a few alloys containing a quasicrystal phase have been identified [10]. Some of them are stable and worthy of investigations concerning their application potential in the engineering domain. The $\mathrm{i}$-phase of $\mathrm{Ti}_{41.5} \mathrm{Zr}_{41.5} \mathrm{Ni}_{17}$ constitutes one such system [11]. As reported, this phase reportedly is capable of storing hydrogen in large quantities and hence is a highly potential candidate for fuel cell application [12]. The i-phase develops in the prior Laves and alpha phase (both HCP) eutectic matrix upon annealing at $570^{\circ} \mathrm{C}$ for seven days [13]. Further annealing at a lower temperature does not cause any transformation of the $\mathrm{i}$-phase. This indicates that the QC phase in question is very stable [11].

Quasicrystals in general are not produced by conventional fabrication techniques. They cannot be formed or cast readily. As stated, the growth of the i-phase in the $\mathrm{Ti}_{41.5} \mathrm{Zr}_{41.5} \mathrm{Ni}_{17}$ alloy also, involves prolonged annealing of the cast ingots. However, alloys having the composition of a QC can be reduced to powder and subsequently can be thermally sprayed to form a thick film coating having the QC phase [14-18]. This phenomenon can be attributed to the rapid quenching associated with the thermal spraying processes.

Only a few reports on corrosion behavior of QCs are available to date $[2,19-21]$. Most of those reports are on aluminum based quasicrystals. The corrosion resistance of Al-based QCs are found to depend upon the composition and microstructure of the QC. Addition of chromium to the quasicrystal improves its corrosion properties [2].

This paper deals with the corrosion aspects of vacuum plasma sprayed quasicrystal $\mathrm{Ti}_{41.5} \mathrm{Zr}_{41.5} \mathrm{Ni}_{17}$ coating. The details of the phases and microstructure of the coating has been addressed in another paper [22] The powder with a size fraction of $-70+10 \mu \mathrm{m}$ has been prepared by gas atomization of the alloy in argon environment. This powder has been vacuum plasma sprayed on 304 stainless steels substrates using a Medicoat $50 \mathrm{KW}$ plasma spraying facility equipped with a 6 axes robot. Before spraying, the substrates have been
TABLE I Parameters for vacuum plasma spraying

\begin{tabular}{lllr}
\hline Sl no. & Parameter & Unit & Value \\
\hline 1 & Chamber pressure & $\mathrm{mbar}$ & 120 \\
2 & Standoff distance & $\mathrm{mm}$ & 400 \\
3 & Primary gas (Ar) flow rate & sl/min & 50 \\
4 & Secondary gas (He) flow rate & sl/min & 10 \\
5 & Arc current & amp & 700 \\
6 & Nozzle diameter & $\mathrm{mm}$ & 6 \\
7 & Powder gas flow & sl/min & 1.3 \\
\hline
\end{tabular}

grit blasted with alumina grits to a surface roughness of $\mathrm{Ra}=5 \mu \mathrm{m}$. The spray parameters are listed in Table $\mathbf{I}$.

For metallographic investigation the polished cross sections of the coating have been examined under a Zeiss DSM 962 Scanning Electron Microscope (SEM). The porosity of the coatings has been estimated by image analysis using the Zeiss KS 400 software.

The corrosion resistance of the coatings has been assessed by both inmersion corrosion testing following the ASTM G 31 standard, and by potentiodynamic measurements (linear sweep voltammetry). Immersion experiments have been done in a $1 \mathrm{M} \mathrm{HCl}$ solution. The corrosion performance of the coating was compared to standard 304 stainless steel (containing 18\% $\mathrm{Cr}$ and $8 \%$ $\mathrm{Ni}$ ). A round area of diameter $12 \mathrm{~mm}$ was exposed to corrosive attack for $24 \mathrm{hrs}$. The mass of the sample was measured prior to testing using a METTLER AT 261 balance having a resolution of $0.01 \mathrm{mg}$. After $24 \mathrm{hrs}$ the specimen was cleaned ultrasonically and the loss of mass was recorded. Tests were repeated twice for stainless steel and four times for the coatings.

Potentiodynamic measurements were performed in both $0.5 \mathrm{M} \mathrm{HCl}+0.5 \mathrm{M} \mathrm{NaCl}$ and $1 \mathrm{M} \mathrm{HCl}$ at $28^{\circ} \mathrm{C}$, using an Autolab PGSTAT 30 potentiostat working with a three electrode set-up. Discs with $15 \mathrm{~mm}$ diameter and about $2.5 \mathrm{~mm}$ thickness, consisting of the plasma sprayed coating of about 500 microns thickness (after polishing) on 304 stainless steel substrate, were mounted on a rotating disc electrode set-up and used as working electrode. For comparison, the corrosion behavior of the quasicrystal $\mathrm{Zr}_{41.5} \mathrm{Ti}_{41.5} \mathrm{Ni}_{17}$ coating was compared to polycrystalline $\mathrm{Zr}_{41.5} \mathrm{Ti}_{41.5} \mathrm{Ni}_{17}$ (GfE Metalle und Materialien $\mathrm{GmbH}$, Germany) and to commercially pure titanium (grade 2), the samples being discs 


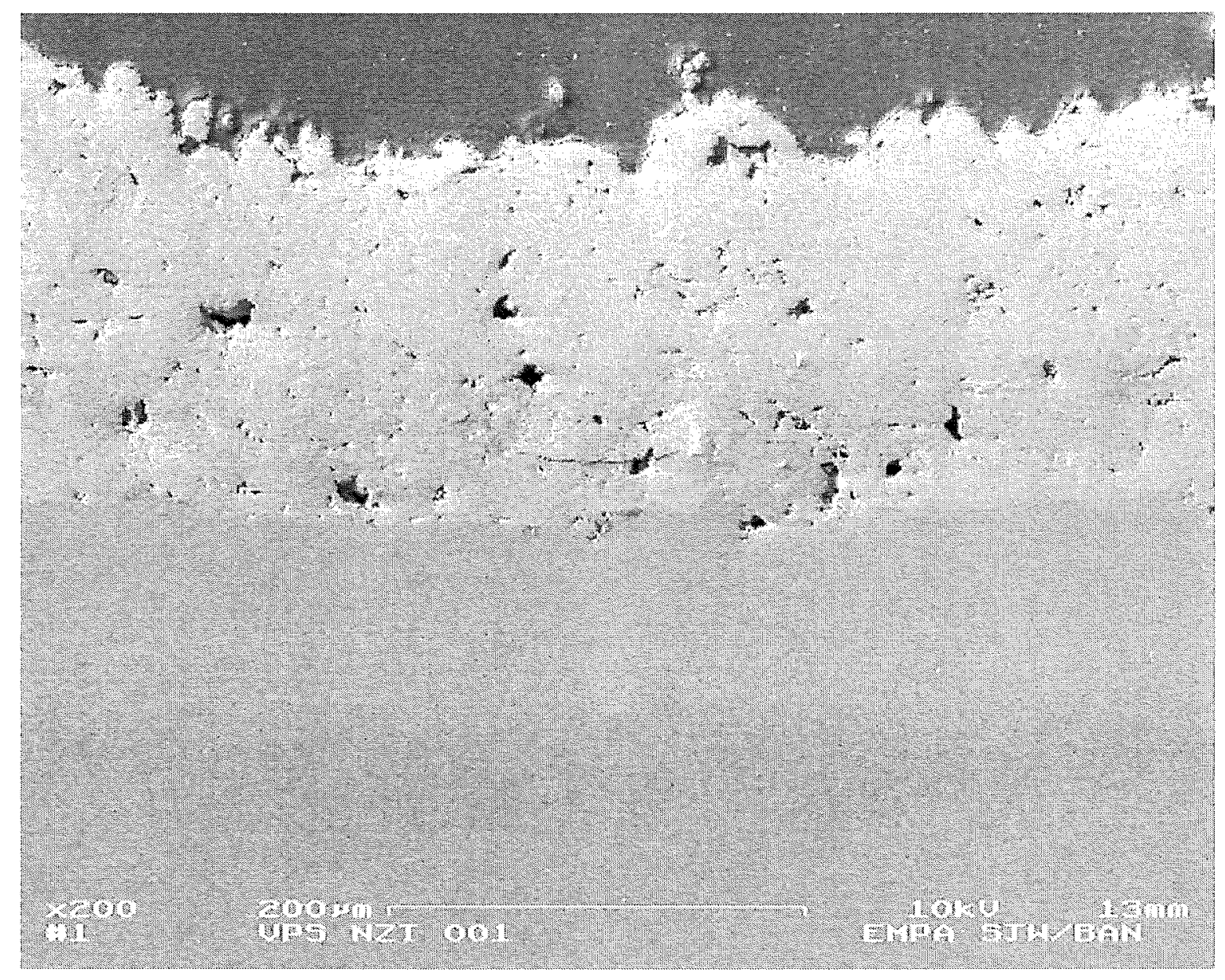

Figure 1 Secondary electron image of the $\mathrm{Ti}_{41.5} \mathrm{Zr}_{41.5} \mathrm{Ni}_{17}$ coating in cross section.

of $15 \mathrm{~mm}$ diameter and $1 \mathrm{~mm}$ thickness. All samples were mechanically polished with 600 grit paper and ultrasonically cleaned in hexane, acetone, ethanol, and deionized water. In each experiment, a total surface of $1.539 \mathrm{~cm}^{2}$ was exposed to the electrolyte. A platinum mesh served as counter electrode and a saturated mercury sulfate electrode ( $\mathrm{SME}, \mathrm{Hg} / \mathrm{Hg}_{2} \mathrm{SO}_{4}$ ) was chosen as reference electrode. All potentials are given with respect to this electrode. Before linear sweep experiments, the working electrodes were prepolarized at $-1.2 \mathrm{~V}$ during $60 \mathrm{~s}$ for additional in-situ cleaning due to the hydrogen evolution at this cathodic potential.

Fig. 1 shows a typical secondary electron image of the cross section of the coating. The estimated porosity of the coating is about $4.9 \%$. The coating is found to adhere well with the substrate. Table II shows the immersion corrosion experiment results. The mass loss of stainless steel is consistently above $3 \mathrm{mg}$ whereas

TABLE II Immersion corrosion test results

\begin{tabular}{lll}
\hline Sample type & Sample no. & Mass loss (mg) \\
\hline 304 stainless steel & 1 & 3.17 \\
& 2 & 3.51 \\
$\mathrm{Ti}_{41.5} \mathrm{Zr}_{41.5} \mathrm{Ni}_{17}$ coating & 1 & 0.28 \\
& 2 & 1.14 \\
& 3 & 0.86 \\
& 4 & 0.12 \\
\hline
\end{tabular}

the maximum mass loss for the coating material under identical conditions is $1.14 \mathrm{mg}$. Clearly the QC alloy offers much higher corrosion resistance than stainless steel under the given conditions.

Linear and logarithmic representations of the measured polarization curves of the quasicrystal coating and of 304 stainless steel in $0.5 \mathrm{M} \mathrm{HCl}+0.5 \mathrm{M} \mathrm{NaCl}$ are given in Figs 2 and 3. This environment with the high chloride concentration is known to favor pitting corrosion, which is a local type of corrosion typicaly

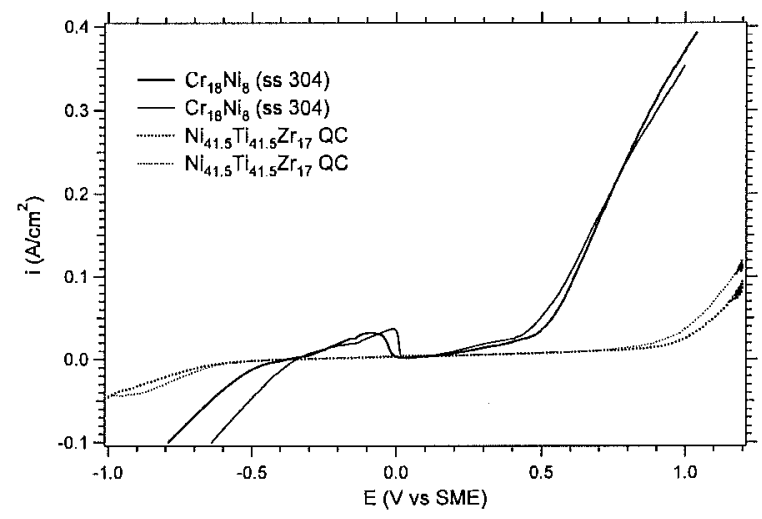

Figure 2 The linear sweep polarization curve of the quasicrystal coating and the stainless steel in $0.5 \mathrm{M} \mathrm{HCl}+0.5 \mathrm{M} \mathrm{NaCl}$. The potential is not corrected for the ohmic drop $(1.27 \Omega)$. 


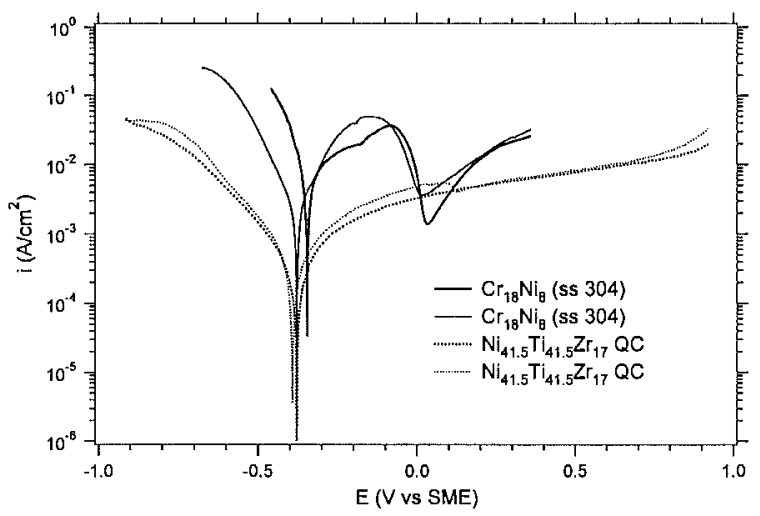

Figure 3 Logarithmic representation of the polarization curve of the quasicrystal coating and the stainless steel in $0.5 \mathrm{M} \mathrm{HCl}+0.5 \mathrm{M} \mathrm{NaCl}$. The potential is corrected for the ohmic drop.

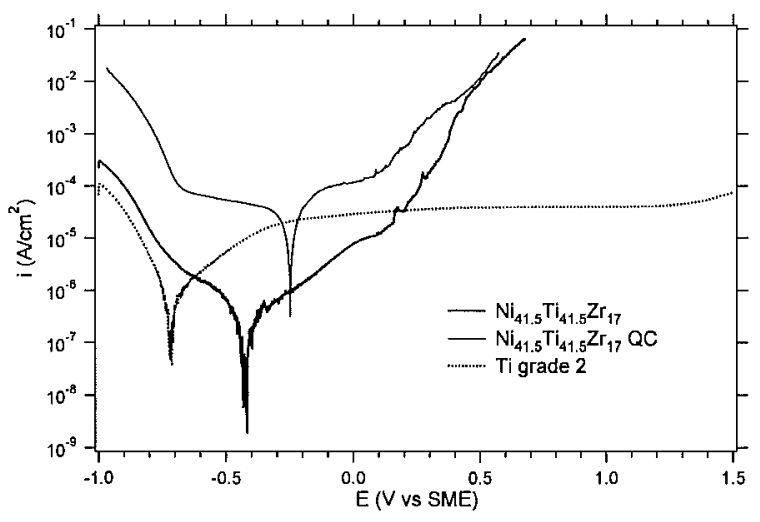

Figure 4 Logarithmic representation of the polarization curve of the quasicrystal coating, the polycrystalline samples of same composition and pure titanium (grade 2) in $1 \mathrm{M} \mathrm{HCl}$. The potential is corrected for the ohmic drop.

occurring on metals protected by a passivating oxide. Fig. 3 shows that the corrosion potentials $E_{\text {corr }}$ of both materials are very similar, but that the corrosion current at $E_{\text {corr }}, i_{\text {corr }}$, is much higher for 304 stainless steel than for the QC coating. The stainless steel shows passiva- tion at potentials above $0 \mathrm{~V}$. It remains passive till the onset of pitting corrosion at potentials above approximately $0.5 \mathrm{~V}$. The quasicrystal coating is passive over the measured range of potentials till the onset of pitting at about $0.85 \mathrm{~V}$. After experiments, QC as well as 304 samples clearly showed corrosion pits. However, the measured current for the QC samples was up to a magnitude lower than for 304 stainless steel, which is in agreement with the better corrosion behavior in immersion tests.

In Fig. 4 polarization curves of the QC coating, the polycrystalline $\mathrm{Zr}_{41.5} \mathrm{Ti}_{41.5} \mathrm{Ni}_{17}$ and titanium in $1 \mathrm{M} \mathrm{HCl}$ are given. It is interesting to note that around the corrosion potential $E_{\text {corr }}$, poly-crystalline $\mathrm{Zr}_{41,5} \mathrm{Ti}_{41.5} \mathrm{Ni}_{17}$ shows even lower anodic currents than titanium, which is very corrosion resistant due to its dense, protecting, oxide layer. However, at more anodic potentials, polycrystalline $\mathrm{Zr}_{41.5} \mathrm{Ti}_{41.5} \mathrm{Ni}_{17}$ is susceptible to pitting corrosion, whereas titanium is not attacked yet. The increase in current for titanium at the anodic end of the measurement is due to the onset of water decomposition in the electrolyte, not to pitting corrosion. By comparing the $\mathrm{QC}$ to the polycrystalline material, higher currents for the QC over the whole range of potentials are found. While both materials are passive at $E_{\text {corr }}$, the oxide of he QC seems to be less protective than that of the polycrystalline material, leading to a larger volume of dissolved material. By comparing UBM micrographs of the corroded surfaces, however, the QC phase seems to play a very important role in the corrosion mechanism. The QC surface (Fig. 5) contains a large number of small pits over the whole surface, resulting in a larger loss of material as seen by the higher currents measured during polarization curves. The polycrystalline surface in Fig. 6 reveals fewer but much larger pits, with an almost intact surface in-between pits. A local attack such as in Fig. 6 is clearly more dangerous with respect to mechanical failure of a device. The combination of polarization curves and surface topography is in this case important to understand the prevailing corrosion mechanism. In spite of the identical chemical composition, both materials

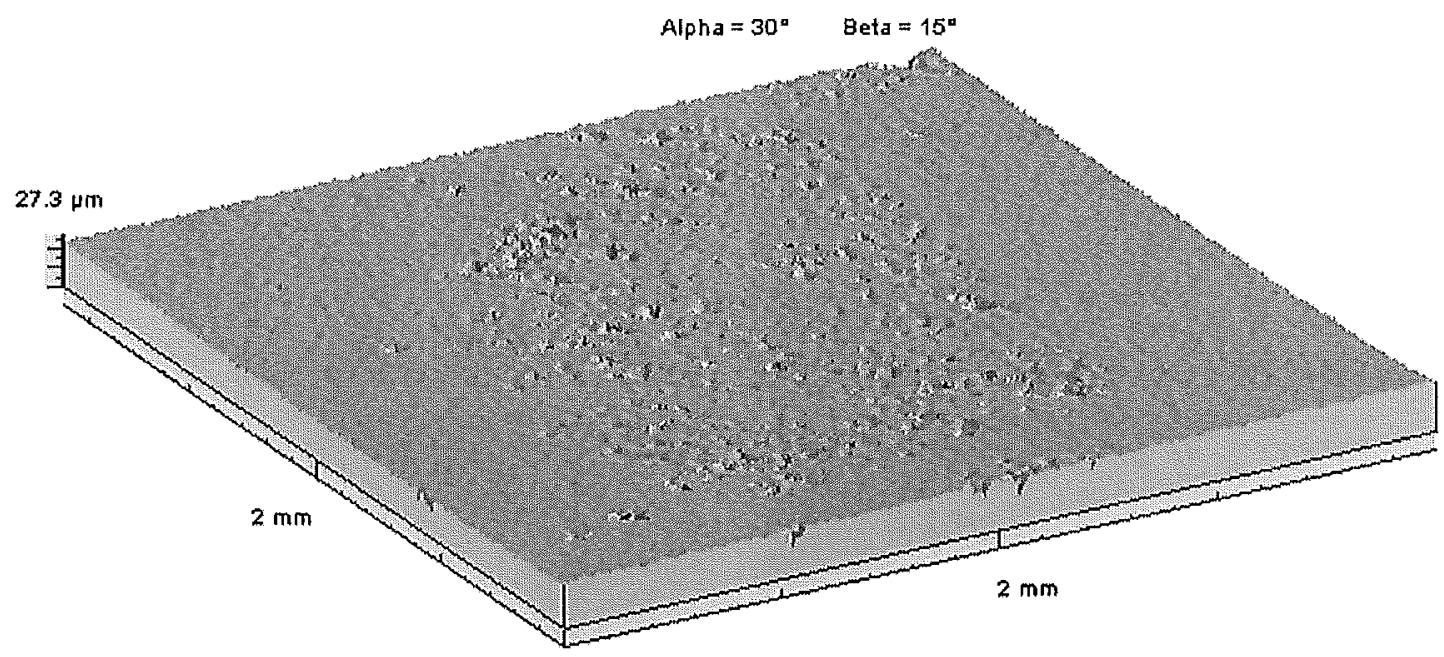

Figure 5 Surface topography measurement by scanning laser profilometry of pitted surface of quasicrystalline $\mathrm{Zr}_{41.5} \mathrm{Ti}_{41.5} \mathrm{Ni}_{17}$ after the linear sweep polarization experiment in Fig. 4. 


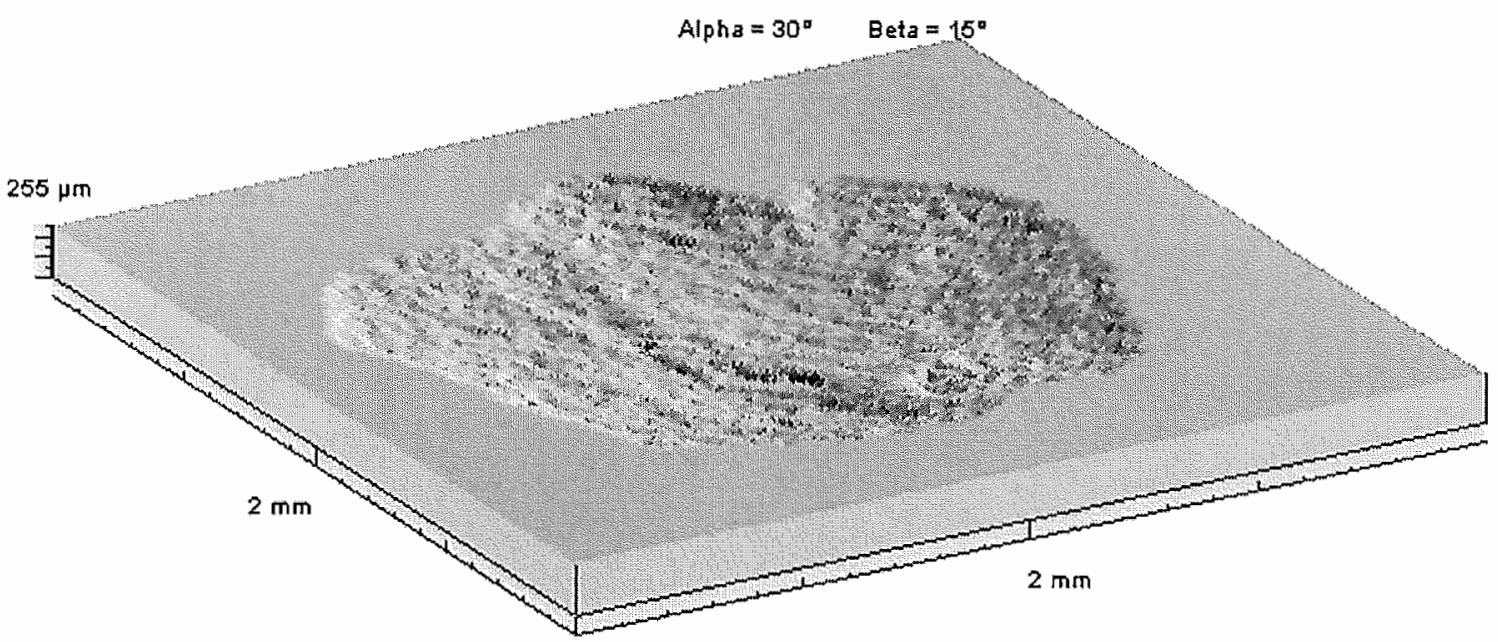

Figure 6 Surface topography measurement by scanning laser profilometry of pitted surface of polycrystalline $\mathrm{Zr}_{41.5} \mathrm{Ti}_{41.5} \mathrm{Ni}_{17}$ after the linear sweep polarization experiment in Fig. 4 (Note the difference in the size of the z-axes between Figs 5 and 6).

show a very different corrosion behavior in chloride environment, which must clearly be due to the differences in their microstructure.

\section{References}

1. D. SHECHTMAN, I, BLECH, D. GRATIAS and J, W. C.AHN, Phys. Rev. Lett. 53 (1984) 1951

2. Y. MASSIANI, S, AIT YAAZZA, J. P. CROUSIER and J. M. DUBOIS, J. Non. Cryst. Sol. 159 (1993) 92.

3. T. KLEIN and O. G. SYMKo, Appl. Phys. Lett. 64 (1994) 431

4. J. M. DUBOIS, S. S. KANG and $S$, VON STEBUT, $J$ Mater: Sci. Letl. 10 (1991) 537.

5. C. J. JENKS and P. A. THEIL, MRS Bull. 22 (1997) 55

6. F. CYROT-LACKMANN, Mater: Sci. Engng. A 294-296(2000) 611.

7. J.-M. DUBOIS, ibid. A 294-296 (2000) 4

8. D. J, SORDELET, S. D. WIDENER, Y. TANG and $M$. F. BESSER, ibid. A 294-296 (2000) 834.

9. J. M. DUBOIS, S. S. KANG and A. PERROT, ibid. A 179180 (1994) 122.

10. D. J. SORDELET, M. F. BESSER andI. E. ANDERSON J. Thermal Spray Techn. 5 (1996) 161

11. J. P. DAVIS, E. H. MAJZOUB, J. M. SIMMONS and K. F. KELTON, Mater: Sci. Engng. A 294-296 (2000) 104.

12. P. A. THIEL, A. I, GOLDMAN and C. J. JENKS, in "Physical Properties of Quasicrystals", edited by Z. M. Stadnik (Springer Series in Solid State Science, Springer-Verlag, Berlin, Germany, 1999) No 126, p. 327.

13. K. F. KELTON, W. J. KIM and R. M. STROUD, Appl. Phys. Lett, 70 (1997) 3230

14. F. J. HERMANEK, in Proceedings of the 1st International Thermal Spray Conference, Montreal, Canada, May 8-11, 2000, edited by C. C. Brandt (ASM International, Materials Park, OH, 2000) p. 567.

15. E. LUGSCHEIDER, C. HERBST-DEDERICHS and A. REIMANN, in Proceedings of the 1st International Thermal Spray Conference, Montreal, Canada, May 8-11, 2000, edited by C. C. Brandt (ASM International, Materials Park, $\mathrm{OH}, 2000$ ) p. 843.

16. A. REIMANN and E. LUGSCHEIDER, in Proceedings of the International Thermal Spray Conference, Singapore, May 28-30, 2001, edited by C. C. Brandt, K. A. Khor and E Lugscheider (ASM International, Materials Park, $\mathrm{OH}, 2001)$ p. 33

17. D. J. SORDELET, P. D. KROTZ, R, L. DANIEL, Jr and M. F. SMITH, in Proceedings of 8th National Thermal Spray Conference, Houston, USA, September 11-15, 1995, edited by C C. Brandt and S. Sampath (ASM International, Materials Park, OH, 1995) p. 627.

18. J. E. SHIELD, A. I. GOLDMAN, I. E. ANDERSON, T. W. ELLIS, R. W. MCCALLUM and D. J. SORDELLET, US Patent \#5,433,978.

19. P. C. GIB B ONS and K. F. KELTON, in Physical Properties of Quasicrystals, edited by Z. M. Stadnik (Springer Series in Solid State Science, Springer-Verlag, Berlin, Germany, 1999) No. 126, p. 403.

20. J. M. DUBOIS, S. S. KANG and Y. MASSIANI, J. Non Crystalline Solids, 153, 1993, 443

21. C. J. JENKS, P. J. PINHERO, S. L. CHANG, J. W. ANDREGG, M. F. BESSER, D. J. DORDELET and P. A. THEIL, in "New Horizons in Quasicrystals," edited by A. I. Goldman, D. J. Sordelet, P. A. Theil and J. M. Dubois (World Scientific, Singapore) p. 157

22. P. P. BANDYOPADHYAY, S. SIEGMANN, C. BEELI and $P$. SCHW ALLER, Submitted

Received 12 March

and accepted 21 April 2004 